\title{
Association of cardiovascular events with glycosylated haemoglobin in diabetic patients
}

\author{
Deo RK ${ }^{1}$, Karki P2 , Sharma SK ${ }^{3}$, Acharya $\mathbf{P}^{4}$
}

${ }^{1}$ Consultant, Army Hospital, Kathmandu, ${ }^{2}$ Professor, ${ }^{3}$ Additional Professor, ${ }^{4}$ Assistant Professor, Department of Internal Medicine, B.P Koirala Institute of Health Sciences, Dharan, Nepal

\begin{abstract}
Background: In persons with diabetes, chronic hyperglycemia (assessed by glycosylated hemoglobin level) is related to the development of microvascular disease; however, the relation of glycosylated hemoglobin (HbA1c) to macrovascular disease is less clear.

Objective: To study the association of cardiovascular events (CVE) with glycosylated haemoglobin in diabetic patients.

Design: Case control study

Setting: B. P. Koirala Institute of Health Sciences (BPKIHS), Dharan, Nepal

Materials and methods: Fifty diabetic patients with recent cardiovascular events: myocardial infarction (MI) or stroke was included in the study. There were 25 patients of myocardial infarction and 25 patients of stroke. Fifty diabetic patients without cardiovascular events were taken as control.

Results: After adjustment for age, smoking, body mass index, systolic blood pressure and total cholesterol at baseline, level of HbA1c was statistically significant $(\mathrm{p}=0.017)$ among patients with CVE. For MI, level of HbA1c was statistically significant $(p=0.018)$ while for stroke, level of HbA1c was not significant $(p=0.694)$. Mean blood glucose also predicted CVE and MI but not stroke in this study ( $\mathrm{p}$ values $=0.006,0.006$ and 0.670 respectively). Fasting and postprandial plasma glucose was statistically significant in CVE ( $\mathrm{p}$ values $=0.024$ and 0.019 respectively). Urine protein was statistically significant for CVE, MI and stroke ( $\mathrm{p}$ values $=0.000,0.032,0.032$ and OR 4.571 (95\% CI: 1.963 10.646), 2.667 (95\% CI: 1.043-6.815), 2.667 (95\% CI: 1.043-6.815) respectively.
\end{abstract}

Limitations: Sample size was limited due to time constraint and limited resources. Cases with peripheral artery disease were not included in the study.

Conclusion: Glycosylated haemoglobin is associated with cardiovascular events and myocardial infarction but not stroke.

Key words: Glycosylated Haemoglobin, Cardiovascular event, Myocardial infarction, Stroke

$\mathrm{D}_{\mathrm{p}}^{\mathrm{i}}$ abetes mellitus is a major and increasing global public health importance ${ }^{1}$. Persons with diabetes are at increased risk for chronic complications which affect many organ systems and are responsible for majority of morbidity and mortality associated with the disease. Chronic complications include vascular complications-Microvascular (retinopathy, neuropathy, and nephropathy) and Macrovascular (coronary artery disease, cerebrovascular disease and peripheral arterial disease $)^{2}$. The risk of chronic complications increases with the duration of hyperglycemia. Because this excess risk is only partially explained by traditional risk factors such as obesity, smoking, dyslipidemia and hypertension, diabetes is often considered as an independent risk factor for cardiovascular disease ${ }^{3}$.
In addition to those risk factors established in the general population, hyperglycemia, unstable plasma glucose levels and glycosylation may play a role in diabetic people ${ }^{4}$.

There has been strong evidence to link chronic hyperglycemia to microvascular complications in persons with diabetes. In randomized clinical trials, improving glycemic control substantially reduces the incidence of microvascular disease in persons

\footnotetext{
Correspondence

Dr. Prahlad Karki

Professor and Head

Department of Internal Medicine

B.P. Koirala Institute of Health Sciences

Ghopa, Dharan, Nepal.

E-mail: prahladkarki@hotmail.com
} 
with diabetes. Evidence implicating causative role for chronic hyperglycemia in the development of macrovascular complications is less conclusive ${ }^{2}$. Results from clinical trials that collected information on cardiovascular outcomes have been equivocal. But diabetic persons have more than two fold increased risk for cardiovascular death compared with persons without diabetes ${ }^{3}$.

Diabetes is a strong risk factor for coronary heart disease, cardiovascular disease and total mortality. The increased risks correlate with fasting and postprandial glucose levels as well as hemoglobin A1c (HbA1c) concentration. HbA1c significantly predicts mortality and cardiovascular disease ${ }^{1}$. The study done to examine the value of Glycosylated haemoglobin (HbA1c) concentration, a marker of blood glucose concentration, as a predictor of death from cardiovascular and all causes in men showed diabetes mellitus increased risk of cardiovascular disease. HbA1c concentrations predict cardiovascular risk in people with diabetes. HbA1c may provide a practical screening tool for diabetes or impaired glucose tolerance ${ }^{5}$.

The present study is thus designed to find out association of Glycosylated haemoglobin with cardiovascular events in diabetic patients.

\section{Materials and methods}

The study was conducted in B. P. Koirala Institute of Health Sciences (BPKIHS), Dharan between April 2005 and March 2006. Fifty consecutive diabetic patients, attending Medicine Out Patients Department, admitted in wards, with recent cardiovascular events like Coronary Heart Disease-Myocardial Infarction or Cerebrovascular Disease-Stroke were included in the study. There were 25 patients of Myocardial Infarction and 25 patients of Cerebrovascular Disease. Fifty diabetic patients admitted in wards, attending OPD for complaints other than Cardiovascular events were taken as control. This was a case control study. All diabetic patients were included in the study. An exclusion criterion was non diabetic patients and patients with bleeding.

Diabetes Mellitus was diagnosed according to WHO criteria: Symptoms of diabetes plus random blood glucose concentration more than or equal to $200 \mathrm{mg} / \mathrm{dL}$ Or Fasting plasma glucose more than or equal to 126 $\mathrm{mg} / \mathrm{dL}$ or Two-hour plasma glucose glucose more than or equal to 200/dL. Random was defined as with regard to time since meal. Fasting was defined as no caloric intake for at least eight hours ${ }^{6,7}$.

The WHO criteria for verified definite or possible myocardial infarction, based on chest pain symptoms, electrocardiographicchangesandenzymedeterminations was used to define myocardial infarction. The WHO criteria for verified definite or possible stroke was used in the ascertainment of the diagnosis of previous stroke, which was defined as a clinical syndrome consisting of neurological symptoms persisting for more than 24 hours ${ }^{8}$.

All the patients were subjected to history and clinical examination according to case proforma. Special attention was given to find out any cardiovascular risk factors like smoking, obesity, and hypertension. Smoking status was based on an interview. In all statistical analyses, subjects were classified as nonsmokers, former smokers or current smokers. Blood pressure was measured to the nearest $2 \mathrm{~mm} \mathrm{Hg}$ with a mercury sphygmomanometer with the subject in the sitting position after a five- minute rest.

Subjects were classified as having hypertension if they were receiving drug treatment for hypertension or if they had a systolic pressure of at least $160 \mathrm{~mm} \mathrm{Hg}$ or a diastolic pressure of at least $95 \mathrm{~mm} \mathrm{Hg}$. Body mass index was calculated by weight in $\mathrm{kg} /$ (height in meter) ${ }^{2}$. Waist hip ratio was also calculated.

A non fasting fresh Ethylene diamine tetra acetic acid (EDTA) sample was collected and sent to lab immediately for analysis of glycosylated haemoglobin. Undue delay was avoided to prevent any hemolysis which might affect glycosylated haemoglobin level concentration. A hemolyzed preparation of the whole blood was mixed continuously for five minutes with weak binding cation-exchange resin. During this time, HbA0 (Nonglycosylated haemoglobin) binds to the resin. After the mixing period, a filter was used to separate the supernatant containing the glycosylated haemoglobin from the resin. The percent glycosylated haemoglobin was determined by measuring the absorbance at $415 \mathrm{~nm}$ of the glycosylated haemoglobin fraction and total haemoglobin fraction. The ratio of the two absorbances gives the percent glycosylated haemoglobin ${ }^{9}$. The level of hyperglycemia was tabulated to find out whether it was related to cardiovascular events or not. Further laboratory examination included Haemogram and Urine Routine and microscopic examination. Fasting and postprandial plasma glucose was determined by the glucose oxidase method. Serum lipids were measured in fresh serum samples.

\section{Statistical analysis}

Data was entered in the Microsoft excel spread sheet. The main outcome variable was CVE and secondary outcome variables MI and stroke. To assess the comparability of both groups, the characteristics of patients in each group at enrollment were compared by 
student $\mathrm{t}$ test for continuous variables and chi-square test for categorical variables. The statistical significance shall be defined as $\mathrm{p}$ value $<0.05$. Analysis was carried out using MS Excel, SPSS software, version 11.5 (SOSS, Inc., Chicago, Illinois) and Epi Info, version 3.2 .

\section{Results}

Fifty diabetic patients with recent history of cardiovascular events were taken as cases which included 25 patients of acute myocardial infarction and 25 patients with stroke. Fifty diabetic patients were matched for age, BMI, smoking, systolic blood pressure and cholesterol with the cases and were taken as control. Baseline characteristics were as shown in the Table 1 and Table 2.

For CVE, $p$ value for intake of anti-diabetic drugs was 0.017, for fasting plasma glucose was 0.024 and for postprandial plasma glucose was 0.019 all of which were statistically significant. For stroke, $\mathrm{p}$ value for mean diastolic blood pressure was 0.026 and for hypertension was 0.003 which were statistically significant. For urine protein, among patients of $\mathrm{CVE}, \mathrm{p}=0.000, \mathrm{OR}=4.571$ (95\% CI: 1.963-10.646); for $\mathrm{MI}, \mathrm{p}=0.032, \mathrm{OR}=2.667$ (95\% CI: 1.043-6.815); for stroke, $\mathrm{p}=0.032, \mathrm{OR}=2.667$ (95\% CI: $1.043-6.815)$.
Among patients with No CV Event, mean HbA1c was 8.45 \pm 1.31 (Range: 5.92-11.41) while among patients with CV Event mean HbA1c was $9.37 \pm 2.33$ (Range: 5.85-14.81), P value 0.017. Among patients with No MI, mean HbA1c was $8.65 \pm 1.68$ (Range: $5.85-13.55$ ) while among patients with MI mean HbA1c was 9.70 \pm 2.43 (Range: 6.37-14.81), P value 0.018. Among patients with No Stroke, mean HbA1c was $8.87 \pm 1.85$ (Range: 5.92-14.81) while among patients with Stroke mean HbA1c was 9.04 \pm 2.25 (Range: 5.85-13.55), P value 0.694 . Overall mean HbA1c was $8.91 \pm 1.94$ (Range: 5.85-14.81).

Among patients with No CV Event, Mean blood glucose was 236.32 \pm 70.16 (Range: 109-427) while among patients with CV Event Mean blood glucose was $307.32 \pm 164.65$ (Range: 105-782), P value: 0.006. Among patients with No MI, Mean blood glucose was $251.4 \pm 100.22$ (Range: 109-637) while among patients with MI Mean blood glucose was 333.08 \pm 185.65 (Range: 131-782), P value: 0.006. Among patients with No Stroke, Mean blood glucose was $268.57 \pm 128.63$ (Range: 109-782) while among patients with Stroke Mean blood glucose was $281.56 \pm 139.63$ (Range: 105637), P value: 0.670 . Overall among all patients, mean blood glucose was $271.82 \pm 130.87$ (Range: 105-782). 
Table 1: Baseline Characteristics of patients with CVE and with No CVE

\begin{tabular}{|c|c|c|c|c|c|}
\hline & CVE & NO CVE & Total & $p$ value & Odds Ratio \\
\hline Age & $61.1 \pm 11.1$ & $56.86 \pm 12.36$ & $58.98 \pm 11.88$ & 0.074 & \\
\hline Sex & & & & 0.420 & $1.176(0.534-2.593)$ \\
\hline Male & $29(58 \%)$ & $27(54 \%)$ & $56(56 \%)$ & & \\
\hline Female & $21(42 \%)$ & $23(46 \%)$ & $44(44 \%)$ & & \\
\hline Smoking & & & & 0.86 & \\
\hline Current & $10(20 \%)$ & $7(14 \%)$ & $17(17 \%)$ & & \\
\hline Former & $20(40 \%)$ & $12(24 \%)$ & $32(32 \%)$ & & \\
\hline Non & $20(40 \%)$ & $31(62 \%)$ & $51(51 \%)$ & & \\
\hline Hypertension & & & & 0.208 & \\
\hline Yes & $32(64 \%)$ & $27(54 \%)$ & $59(59 \%)$ & & \\
\hline No & $18(36 \%)$ & $23(46 \%)$ & $41(41 \%)$ & & \\
\hline Diabetic drug & & & & 0.017 & \\
\hline OHA & $29(58 \%)$ & $40(80 \%)$ & $69(69 \%)$ & & \\
\hline Insulin & $6(12 \%)$ & $6(12 \%)$ & $12(12 \%)$ & & \\
\hline Non & $15(30 \%)$ & $4(8 \%)$ & $19(19 \%)$ & & \\
\hline $\begin{array}{l}\text { Diabetes } \\
\text { duration }\end{array}$ & & & & 0.312 & \\
\hline$<1$ year & $18(36 \%)$ & $17(34 \%)$ & $35(35 \%)$ & & \\
\hline $1-10$ yrs & $18(36 \%)$ & $25(50 \%)$ & $43(43 \%)$ & & \\
\hline$>10 \mathrm{yrs}$ & $14(28 \%)$ & $8(16 \%)$ & $22(22 \%)$ & & \\
\hline BMI & $23.38 \pm 2.57$ & $23.94 \pm 4.02$ & $23.66 \pm 3.37$ & 0.417 & \\
\hline Waist Hip Ratio & & & & 0.522 & \\
\hline Male $<1.0$ & $28(56 \%)$ & $26(52 \%)$ & $54(54 \%)$ & & \\
\hline Male $>1.0$ & $1(2 \%)$ & $1(2 \%)$ & $2(2 \%)$ & & \\
\hline Female $<.9$ & $7(14 \%)$ & $7(14 \%)$ & $14(14 \%)$ & & \\
\hline Female $>0.9$ & $14(28 \%)$ & $16(32 \%)$ & $30(30 \%)$ & & \\
\hline Systolic BP & $131.36 \pm 18.27$ & $130.92 \pm 15.23$ & $131.4 \pm 16.74$ & 0.896 & \\
\hline Diastolic BP & $83.56 \pm 11.29$ & $82.48 \pm 9.2$ & $83.02 \pm 10.26$ & 0.601 & \\
\hline Fasting PG & $164.86 \pm 65.84$ & $137.68 \pm 51.45$ & $151.27 \pm 60.35$ & 0.024 & \\
\hline Postprandial PG & $256.62 \pm 81.29$ & $220.54 \pm 69.75$ & $238.58 \pm 77.51$ & 0.019 & \\
\hline Urine Protein & & & & 0.000 & $4.571(1.963-10.646)$ \\
\hline Present & $32(64 \%)$ & $14(28 \%)$ & $46(46 \%)$ & & \\
\hline Absent & $18(36 \%)$ & $36(72 \%)$ & $54(54 \%)$ & & \\
\hline Cholesterol & $162.48 \pm 56.77$ & $162.64 \pm 36.50$ & $162.56 \pm 47.48$ & 0.987 & \\
\hline HDL & $39.28 \pm 7.79$ & $42.02 \pm 9.92$ & $162.56 \pm 47.48$ & 0.128 & \\
\hline TAG & $117.76 \pm 56.36$ & $132.16 \pm 62.50$ & $124.96 \pm 59.65$ & 0.229 & \\
\hline LDL & $86.24 \pm 34.09$ & $91.34 \pm 32.75$ & $88.79 \pm 33.36$ & 0.447 & \\
\hline
\end{tabular}


Table 2: Baseline Characteristics of patients with MI and with Stroke

\begin{tabular}{|c|c|c|c|c|c|c|}
\hline & MI & No MI & p value & Stroke & No Stroke & $p$ value \\
\hline Age & $60.36 \pm 11.32$ & $58.52 \pm 12.10$ & 0.505 & $61.84 \pm 11.05$ & $58.03 \pm 12.06$ & 0.166 \\
\hline Sex & & & 0.590 & & & 0.410 \\
\hline Male & $14(56 \%)$ & $42(56 \%)$ & & $15(60 \%)$ & $41(54.66 \%)$ & \\
\hline Female & $11(44 \%)$ & $33(44 \%)$ & & $10(40 \%)$ & $34(45.33 \%)$ & \\
\hline Smoking & & & 0.67 & & & 0.54 \\
\hline Current & $7(28 \%)$ & $10(13.33 \%)$ & & $3(12 \%)$ & $14(18.66 \%)$ & \\
\hline Former & $10(40 \%)$ & $22(29.33 \%)$ & & $10(40 \%)$ & $22(29.33 \%)$ & \\
\hline Non & $8(32 \%)$ & $43(57.33 \%)$ & & $12(48 \%)$ & $39(52 \%)$ & \\
\hline Hypertension & & & 0.064 & & & 0.003 \\
\hline Yes & $11(44 \%)$ & $48(64 \%)$ & & $21(84 \%)$ & $38(50.66 \%)$ & \\
\hline No & $14(56 \%)$ & $27(36 \%)$ & & $4(16 \%)$ & $37(49.33 \%)$ & \\
\hline Diabetic drug & & & 0.404 & & & 0.151 \\
\hline OHA & $15(60 \%)$ & $54(72 \%)$ & & $14(56 \%)$ & $55(73.33 \%)$ & \\
\hline Insulin & $3(12 \%)$ & $9(12 \%)$ & & $3(12 \%)$ & $9(12 \%)$ & \\
\hline Non & $7(28 \%)$ & $12(16 \%)$ & & $8(32 \%)$ & $11(14.66 \%)$ & \\
\hline $\begin{array}{l}\text { Diabetes } \\
\text { duration }\end{array}$ & & & 0.752 & & & 0.396 \\
\hline$<1$ year & $8(32 \%)$ & $27(36 \%)$ & & $10(40 \%)$ & $25(33.33)$ & \\
\hline 1-10 yrs & $10(40 \%)$ & $33(44 \%)$ & & $8(32 \%)$ & $35(46.66 \%)$ & \\
\hline$>10$ yrs & $7(28 \%)$ & $15(20 \%)$ & & $7(28 \%)$ & $15(20 \%)$ & \\
\hline BMI & $22.68 \pm 2.62$ & $23.99 \pm 3.54$ & 0.092 & $24.09 \pm 2.37$ & $23.52 \pm 3.64$ & 0.461 \\
\hline Waist Hip Ratio & & & 0.726 & & & 0.275 \\
\hline Male $<1.0$ & $13(52 \%)$ & $41(54.66 \%)$ & & $15(60 \%)$ & $39(52 \%)$ & \\
\hline Male $>1.0$ & $1(4 \%)$ & $1(1.33 \%)$ & & $0(0 \%)$ & $2(2.66 \%)$ & \\
\hline Female $<.9$ & $3(12 \%)$ & $11(14.66 \%)$ & & $4(16 \%)$ & $10(13.33 \%)$ & \\
\hline Female $>0.9$ & $8(32 \%)$ & $22(29.33 \%)$ & & $6(24 \%)$ & $24(32 \%)$ & \\
\hline Systolic BP & $126.88 \pm 22.33$ & $132.56 \pm 14.31$ & 0.143 & $135.84 \pm 11.90$ & $129.57 \pm 17.86$ & 0.105 \\
\hline Diastolic BP & $80.16 \pm 13.06$ & $83.97 \pm 9.04$ & 0.108 & $86.96 \pm 8.1$ & $81.7 \pm 10.61$ & 0.026 \\
\hline Fasting PG & $163.84 \pm 67.15$ & $147.08 \pm 57.78$ & 0.231 & $165.88 \pm 65.86$ & $146.4 \pm 58.05$ & 0.163 \\
\hline Postprandial PG & $257.16 \pm 84.69$ & $232.38 \pm 74.53$ & 0.168 & $256.49 \pm 79.46$ & $232.74 \pm 76.48$ & 0.194 \\
\hline Urine Protein & & & 0.032 & & & 0.032 \\
\hline Present & $16(64 \%)$ & $30(40 \%)$ & & $16(64 \%)$ & $30(40 \%)$ & \\
\hline Absent & $9(36 \%)$ & $45(60 \%)$ & & $9(36 \%)$ & $45(60 \%)$ & \\
\hline Cholesterol & $169.92 \pm 68.68$ & $160.10 \pm 38.24$ & 0.374 & $155.04 \pm 41.80$ & $165.06 \pm 49.23$ & 0.363 \\
\hline HDL & $38.52 \pm 6.72$ & $41.36 \pm 9.55$ & 0.172 & $40.04 \pm 8.80$ & $40.85 \pm 9.09$ & 0.697 \\
\hline TAG & $124 \pm 62.42$ & $125.28 \pm 59.13$ & 0.927 & $111.52 \pm 50.09$ & $129.44 \pm 62.17$ & 0.197 \\
\hline LDL & $91.76 \pm 39.92$ & $87.8 \pm 31.11$ & 0.610 & $80.72 \pm 26.76$ & $91.48 \pm 35.03$ & 0.164 \\
\hline
\end{tabular}

Table 3: HbA1c and mean blood glucose level in different study arms

\begin{tabular}{|c|c|c|c|c|}
\hline & HbA1c & p value & Mean blood glucose & p value \\
\hline CVE & $9.37 \pm 2.33$ & \multirow{2}{*}{0.017} & $307.32 \pm 164.65$ & \multirow{2}{*}{0.006} \\
\hline NO CVE & $8.45 \pm 1.31$ & & $236.32 \pm 70.16$ & \\
\hline MI & $9.70 \pm 2.43$ & \multirow{2}{*}{0.018} & $333.08 \pm 185.65$ & \multirow{2}{*}{0.006} \\
\hline No MI & $8.65 \pm 1.68$ & & $251.4 \pm 100.22$ & \\
\hline Stroke & $9.04 \pm 2.25$ & \multirow{2}{*}{0.694} & $281.56 \pm 139.63$ & \multirow{2}{*}{0.670} \\
\hline \begin{tabular}{|l} 
No Stroke \\
\end{tabular} & $8.87 \pm 1.85$ & & $268.57 \pm 128.63$ & \\
\hline
\end{tabular}




\section{Discussion}

Diabetes is a strong risk factor for cardiovascular diseases. The increased risk correlate with fasting and postprandial glucose levels as well as hemoglobin A1c (HbA1c) concentration. HbA1c significantly predicts mortality and cardiovascular diseases ${ }^{1}$.

Available data support a moderate increase in cardiovascular risk with increasing levels of glycosylated hemoglobin in persons with diabetes mellitus. This association seems to be similar in persons with type 1 and type 2 diabetes and is present across diverse geographic populations. In some studies, this association seems to be independent of other known risk factors for cardiovascular disease ${ }^{2}$.

The present study was designed to look at association of chronic hyperglycemia as measured by HbA1c level with cardiovascular events (CVE) namely myocardial infarction (MI) and stroke.

The study took two groups of patients for assessing the association of $\mathrm{HbAlc}$ with CVE. The study group had recent $\mathrm{CVE}$ and the control group did not have any history of CVE. The control group was matched for age, smoking, BMI, systolic blood pressure and total cholesterol with the study group.

Advancing age is a proven risk factor for CVE. Thus in present study patients were matched for age among two groups. The mean age of patients with CVE was $61.1 \pm 11.1$ years and that in patients with NO CVE mean age was $56.86 \pm 12.36$ years.

Alderberth et al. ${ }^{4}$ showed that smoking almost doubled the risk for mortality from coronary heart disease (CHD) in diabetic as well as non-diabetic men. Hagman et al. ${ }^{10}$ also showed that smoking is an important risk factor for CVE mortality in diabetic subjects. Thus to nullify the effect of smoking on CVE, in the present study the patients were matched for smoking status.

Alderberth et $\mathrm{al}^{4}$ found no association between BMI and CHD or all cause mortality among diabetic men. Fontbonne et $\mathrm{al}^{11}$ found an increased risk for early mortality in obese diabetic subjects. BMI was positively associated with CHD mortality but not with all-cause mortality in diabetic people according to Morrish et $\mathrm{al}^{12}$. Sasaki et $\mathrm{al}^{13}$ found negative associations between BMI and all-cause and CHD mortality. BMI was not associated with 15 year CHD mortality among diabetic men in the Whitehall Study, Fitzgerald et al ${ }^{14}$ and Uusitupa et $\mathrm{al}^{15}$ found no impact of baseline BMI on 10 year CHD mortality. Yusuf et $\mathrm{al}^{16}$ concluded that BMI showed a modest and graded association with myocardial infarction which was substantially reduced after adjustment for waist-to-hip ratio and non-significant after adjustment for other risk factors. The range for acceptable, normal, or optimum BMI for Asian populations should be narrowed to 18.5-23 $\mathrm{kg} / \mathrm{m}^{2}$, according to a WHO expert consultation on appropriate BMI for these populations. In the present study owing to these conflicting reports, the patients were matched for BMI.

Fuller et $\mathrm{al}^{17}$ in the Whitehall Study showed that systolic blood pressure was a significant predictor for CHD and all cause mortality after 15 years of follow up. Alderberth et $\mathrm{al}^{4}$ also showed that high systolic blood pressure was associated with an increase of relative risk of dying from CHD. In the present study patients were matched for systolic blood pressure among cases and control groups.

Alderberth etal ${ }^{4}$ showedhypercholesterolemia, smoking, and high blood pressure as independent risk factors also within a diabetic population. Men with diabetes and severe hypercholesterolemia have a particularly poor prognosis. Kannel et $\mathrm{al}^{18}$ in the Framingham Study showed that elevated serum cholesterol was a risk factor for CVE and/or death among diabetic people. In the present study, the two groups of patients were matched for total cholesterol. While on analysis of HDL, TAG and LDL, there was no significance.

Janghorbani et $\mathrm{al}^{19}$ and Park et $\mathrm{al}^{20}$ showed for glycemic variables with CVE mortality separately, the associations were stronger in women than in men. De Vegt et $\mathrm{al}^{21}$ showed no clear consistent differences between men and women though. In the present study, among patients with No CVE, $46 \%$ were female and $54 \%$ were male while among patients with CVE, $42 \%$ were female and $58 \%$ were male. There was no difference between male and female for CVE. (p value: 0.42 ).

Cook et $\mathrm{al}^{22}$ in Framingham study reported that hypertension has a greater significance in predicting mortality in diabetic compared with non-diabetic subjects while Kannel et $\mathrm{al}^{18}$ reported a similar significance in predicting mortality in diabetic compared with non-diabetic subjects. In this study hypertension was significant in predicting stroke but not CVE ( $p$ value $0.003)$. In the present study diastolic blood pressure predicted occurrence of stroke ( $p$ value: 0.026 ) but not CVE or MI.

In the present study intake of any anti-diabetic drugs insulin or OHA was associated with lesser frequency of having CVE ( $p$ value: 0.017 ). This suggests that patients on anti-diabetic drug had lesser degree of glycemia.

Spijkerman et $\mathrm{al}^{23}$ showed that mortality risk increased with increasing diabetes duration. In subjects with 
longer diabetes duration, the elevated mortality risk was independent of other cardiovascular risk factors compared to subjects with short diabetes duration, in whom the association could largely be attributed to cardiovascular risk factors. Muggeo et $\mathrm{al}^{24}$ showed that type 2 diabetes is usually recognized 5-12 years after hyperglycemia develops. Similarly Letter et $\mathrm{a}^{25}$ showed that prevalence of undiagnosed diabetes was $2.2 \%$ in the study patients. In the present study patients were grouped into three groups with diabetes duration less than one year, between one to ten years and more than 10 years. But there was no significant correlation between any three groups regarding CVE. It was not possible to find out exact duration of diabetes in these patients as patients in this part may not be coming for checkup early in the course of disease to be diagnosed early. Lack of practice for screening of patients for early diagnosis may also play part. Thus though no significant correlation was found for CVE according to duration of diabetes, the interpretation should be made with caution.

Obesity is a major risk factor for cardiovascular diseases. Dietary fat may have an effect on glycemia through obesity. High fat intake may be related to obesity which is in turn associated with insulin resistance. Harding et $\mathrm{al}^{26}$ demonstrated consistent associations between both the pattern and total intake of dietary fat and the level of $\mathrm{HbAlc}$ across the normal range of $\mathrm{HbAlc}$. Uusitupa et $\mathrm{al}^{15}$ found that along with BMI, Waist Hip ratio had no impact on 10-year CHD mortality. Yusuf et $\mathrm{al}^{27}$ proved that waist hip ratio (WHR) was stronger indicator of myocardial infarction than BMI. WHR showed a graded and highly significant association with myocardial infarction risk worldwide. Ramachandran et $\mathrm{al}^{28}$ showed that in a comparative study of the non diabetic Asian Indians and Mexican Americans, although the former had a much lower BMI than the Mexican Americans, they had upper body adiposity measured as WHR, comparable to that of Mexican Americans. Ramachandran et $\mathrm{al}^{29}$ observed a significantly lower BMI in the rural than in the urban population, but both the groups had similar WHR. The present study did not reveal any association between WHR and CVE.

Microalbuminuria is the first sign of renal dysfunction in diabetic patients Ruggenenti et $\mathrm{al}^{30}$. Dinneen et $\mathrm{al}^{31}$ showed that in patients with diabetes and renal disease, lowering blood pressure and the levels of urinary albumin is effective in reducing the risk of end-stage renal disease as well as that of myocardial infarction, heart failure, and stroke. In the present study proteinuria significantly predicted all CVE, MI and stroke ( $\mathrm{p}$ values: $0.000,0.032$, and 0.032 respectively). This correlates well with other study that proteinuria predicts CVE.

DeVegt et $\mathrm{al}^{21}$ showed that there was no clear independent association between fasting plasma glucose and CVE but postprandial plasma glucose and HbA1c were associated with CVE and mortality even within the non-diabetic range. Meigs et $\mathrm{al}^{32}$ found that fasting and postprandial plasma glucose individually increased risk for incident CVE, even after accounting for standard non-glycemic cardiovascular risk factors. The original Framingham Heart Study cohort also found that fasting and postprandial plasma glucoses was associated with increases CVE, Singer et $\mathrm{al}^{33}$. The DECODE (Diabetes Epidemiology: Collaborative Analysis of Diagnostic Criteria in Europe) Study Group ${ }^{34}$ found that after adjustment for standard cardiovascular disease risk factors, the fasting plasma glucose level did not independently increase risk for cardiovascular mortality but the postprandial plasma glucose level was a significant independent predictor. Coutinho et $\mathrm{al}^{35}$ found a graded relationship between the initial fasting and postprandial glucose level and the subsequent 12year occurrence of a cardiovascular event.

In the present study fasting plasma glucose as well as postprandial plasma glucose significantly predicted CVE ( $p$ value for fasting plasma glucose was 0.024 and $\mathrm{p}$ value for postprandial plasma glucose was 0.019 ).

Edelman et $\mathrm{al}^{36}$ showed that in an outpatient population undergoing screening in a health care setting, HbAlc strongly predicts the development of diabetes. Khaw et $\mathrm{al}^{1}$ showed that Hemoglobin A1c significantly predicted all-cause mortality and coronary and cardiovascular disease, even below the threshold commonly accepted for the diagnosis of diabetes and independent of age and classic risk factors. Blake et $\mathrm{al}^{37}$ found that baseline levels of $\mathrm{HbA} 1 \mathrm{c}$ were a strong predictor of cardiovascular risk in a large cohort of generally healthy women without diabetes mellitus. These data support the need for further research to investigate the temporal relationship between glycemic control and the development of other cardiovascular risk factors. UKPDS $33^{38}$ found that an intensive blood-glucose-control policy with an $11 \%$ reduction in median $\mathrm{HbA} 1 \mathrm{c}$ over the first ten years decreased the frequency of some clinical complications of type 2 diabetes. The intensive treatment group had a substantial $25 \%$ reduction in the risk of microvascular endpoints. There was evidence of a $16 \%$ risk reduction $(p=0.052)$ for myocardial infarction, which included non-fatal and fatal myocardial infarction and sudden death.

Kuusisto et $\mathrm{al}^{39}$ found that in patients with type 2 diabetes, glycemic control influences cardiovascular risk, including the risk for CHD, independent of conventional risk. DeVegt et $\mathrm{al}^{21}$ showed that high glycemic variables, especially postprandial plasma glucose concentrations and to a lesser extent HbAlc values, may be indicators of increased risk of cardiovascular disease mortality 
in a general older population without known diabetes. Meigs et $\mathrm{al}^{32}$ found that fasting, postprandial and average hyperglycemia (assessed by HbA1c) all individually increased risk for incidences of cardiovascular disease events, even after accounting for standard non-glycemic cardiovascular disease risk factors. Park et $\mathrm{al}^{20}$ concluded that glycosylated haemoglobin is a better predictor of cardiovascular disease and ischemic heart disease mortality than fasting plasma glucose or postprandial plasma glucose in women without diabetes, no single measure of glycemia was predictive in men.

In the present study, among patients with CVE and No CVE, level of HbA1c was statistically significant $(p=0.017)$. For MI, level of HbA1c was statistically significant $(\mathrm{p}=0.018)$ while for that of stroke, level of HbA1c was not significant $(\mathrm{p}=0.694)$. Thus the present study is consistent with the fact observed from other studies that HbAlc levels predict CVE as well as MI, though this study did not predict stroke.

Similarly mean blood glucose also predicted CVE, MI but not stroke in the present study. P values were 0.006 , 0.006 and 0.670 respectively. Cardiovascular events include CAD, stroke as well as peripheral arterial disease. Levin et $\mathrm{al}^{40}$ has suggested that peripheral arterial disease is both a macrovascular and microvascular disease, although this is controversial. Meta analysis done by Selvin et $\mathrm{al}^{3}$ showed that compared with coronary heart disease and stroke, the pooled results of the few studies on glycosylated hemoglobin and peripheral arterial disease in persons with type 1 and type 2 diabetes suggest the possibility of a stronger association between glycosylated hemoglobin levels and peripheral arterial disease. Olson et $\mathrm{al}^{41}$ showed that diabetes duration, glycemia, heart rate, and renal status independently predicted lower extremity arterial disease events in type 1 DM. And glycosylated hemoglobin independently predicted lower extremity arterial disease events in men.

Due to logistic problem of diagnosis, peripheral arterial disease was not included in present study of CVE. Haffner et $\mathrm{al}^{8}$ showed that both diabetic and non-diabetic subjects with prior MI have an increased incidence of cardiovascular events. Diabetic subjects had much higher mortality from CHD than non-diabetic subjects. They also showed that patients with type 2 diabetes who have not had MI have a risk of MI similar to that among non-diabetic patients who have had a prior MI. Thus diabetes could be included as a risk equivalent to prior acute coronary events. Blake et $\mathrm{al}^{37}$ showed that baseline levels of HbAlc were a strong predictor of future cardiovascular events in crude analyses.

Kuusisto et $\mathrm{al}^{39}$ showed in patients with type 2 diabetes, glycemic control influences cardiovascular risk, including the risk for $\mathrm{CHD}$, independently of conventional risk factors. The Diabetes Control and Complications Trial (DCCT) $1993^{42}$ established that tight blood glucose control could reduce the incidence of microvascular complications in type $1 \mathrm{DM}$.

UKPDS $33^{38}$ showed Intensive blood-glucose control by either sulphonylureas or insulin substantially decreases the risk of microvascular complications, but not macrovascular disease, in patients with type 2 diabetes.

DCCT published in $2005^{43}$ showed that Intensive treatment reduced the risk of any cardiovascular disease event by 42 percent and the risk of nonfatal myocardial infarction, stroke, or death from cardiovascular disease by 57 percent. This proved that Intensive diabetes therapy has long term beneficial effects on the risk of cardiovascular disease in patients with type 1 diabetes.

The decrease in glycosylated hemoglobin values during the DCCT was significantly associated with most of the positive effects of intensive treatment on the risk of cardiovascular disease.

Because of time constraint and limited resources, adequate sample size could not be taken. Since similar study has not been done in this part of the world, the data available in western world was taken for sample size calculation, which may not be applicable in this part of the world. Therefore, this study may be taken as pilot study in this regards and further study need to be carried out for further elaboration. Also due to logistic and diagnostic problem, cases with peripheral artery disease could not be included in the study.

\section{Conclusion}

The present study shows that in a group of patients matched for age, BMI, smoking, systolic blood pressure and total cholesterol levels, measuring HbAlc levels predicted the CVE as well as MI but did not predict stroke.

\section{References}

1. Khaw KT, Wareham N, Bingham S, Luben R, Oakes S, Welch A et al. Association of Haemoglobin A1c with cardiovascular disease and Mortality in Adults: The European Prospective Investigation into cancer in Norfolk. Ann Intern Med. 2004;141:413-20.

2. Powers AC. Diabetes Mellitus. In: Kasper DL, Braunwald E, Fauci AS, Hauser SL, Longo DL, Jameson JL, editors. Harrison's Principles of Internal Medicine. $16^{\text {th }}$ Ed. USA: The McGraw Hill Companies Inc; 2005. P. 2152-80. 
3. Selvin E, Marinopoulos S, Berkenblit G, Rami T, Brancati FL, Powe NR, et al. Meta-Analysis: Glycosylated Hemoglobin and Cardiovascular Disease in Diabetes Mellitus. Ann Intern Med. 2004;141:421-31.

4. Adlerberth AM, Rosengren A, Wilhelmsen L. Diabetes and Long-Term Risk of Mortality from Coronary and Other Causes in MiddleAged Swedish Men: A general population study. Diabetes Care 1998 April;21:539-45.

5. Khaw KT, Wareham N, Luben R, Bingham S, Oakes S, Welch A, et al. Glycated haemoglobin, diabetes, and mortality in men in Norfolk cohort of European Prospective Investigation of Cancer and Nutrition (EPIC-Norfolk). BMJ 2001;322:15-8

6. WHO. Diabetes mellitus: report of a WHO study group. Geneva: WHO Tech Rep Ser 1985;727:1-113.

7. Kuzuya T, Nakagawa S, Satoh J, Kanazawa Y, Iwamoto Y, Kobayashi M, et al. Report of the Committee on the classification and diagnostic criteria of diabetes mellitus. Diabetes Research and Clinical Practice 2002;55:65-85.

8. Haffner SM, Lehto S, Ronnemaa T, Pyorala K, Lakkso M. Mortality from coronary heart disease in subjects with type 2 diabetes and in non-diabetic subjects with and without prior myocardial infarction. $\mathrm{N}$ Engl J Med 1998;339:229-34.

9. Pointe Scientific, Inc.-Glycohaemoglobin Reagent Set manual

10. Hagman M, Wilhelmsen L, Wedel H, Pennert K. Risk factors for angina pectoris in a population study of Swedish men. J Chronic Dis. 1987;40:265-75.

11. Fontbonne A, Thibult N, Eschwège E, Ducimetière P. Body fat distribution and coronary heart disease mortality in subjects with impaired glucose tolerance or diabetes mellitus: the Paris Prospective Study, 15-year follow-up. Diabetologia 1992;35:464-8.

12. Morrish NJ, Stevens LK, Head J, Fuller JH, Jarrett RJ, Keen H. A prospective study of mortality among middle-aged diabetic patients (the London cohort of the WHO Multinational Study of Vascular Disease in Diabetics) II: associated risk factors. Diabetologia 1990;33:542-48.

13. Sasaki A, Horiuchi N, Hasegawa K, Uehara M. Mortality and causes of death in type 2 diabetic patients: a long-term follow-up study in Osaka District, Japan. Diab Res Clin Pract.1989;7:3340.
14. Fitzgerald AP, Jarrett RJ. Are conventional risk factors for mortality relevant in type 2 diabetes? Diabetic Med. 1991;8:475-80.

15. Uusitupa MIJ, Niskanen LK, Voutilainen E, Pyörälä K. Ten-year cardiovascular mortality in relation to risk factors and abnormalities in lipoprotein composition in type 2 (non-insulindependent) diabetic and non-diabetic subjects. Diabetologia.1993;36:1175-84.

16. Leiter LA, Barr A, Belanger A, Lubin S, Ross SA, Tildesley HD, et al. Diabetes Screening in Canada (DIASCAN) Study: Prevalence of undiagnosed diabetes and glucose intolerance in family physician offices. Diabetes Care 2001;24:1038-43.

17. Fuller JH, Shipley MJ, Rose G, Jarrett RJ, Keen H. Mortality from coronary heart disease and stroke in relation to degree of glycaemia: the Whitehall Study. Br Med J 1983;287:867-70.

18. Kannel WB, McGee DL. Diabetes and cardiovascular risk factors: the Framingham Study. Circulation 59:8-13, 1979 population study of Swedish men. J Chronic Dis. 1987; 40:265-75.

19. Janghorbani M, Jones RB, Gilmour WH, Hedley AJ, Zhianpour M. A prospective population based study of gender differential in mortality from cardiovascular disease and 'all causes' in asymptomatic hyperglycaemics. J Clin Epidemiol. 1994;47:397-405.

20. Park S, Barrett-Connor E, Wingard DL, Shan $\mathrm{J}$, Edelstein $\mathrm{S}$. $\mathrm{GHb}$ is a better predictor of cardiovascular disease than fasting or postchallenge plasma glucose in women without diabetes. The Rancho Bernardo Study. Diabetes Care 1996;19:450-5.

21. de VegtF, Dekker JM, Ruhe HG, Stehou-wer CD, Nijpels G, Bouter LM, et al. Hyperglycaemia is associated with all-cause and cardiovascular mortality in the Hoorn population: the Hoorn Study. Diabetologia 1999;42:926-31.

22. Cook DG, Shaper AG, Macfarlane PW, Goodkin G. Mortality factors in diabetics. J Occup Med.1975;17:716-21.

23. Spijkerman AMW, Dekker JM, Nijpels G, Jager A, Kostense PJ, van Hinsbergh VWM, et al. Impact of diabetes duration and cardiovascular risk factors on mortality in type 2 diabetes: the Hoorn Study. European Journal of Clinical Investigation 2002;32:924-30.

24. Muggeo M. Accelerated complications in type 2 diabetes mellitus: the need for greater awareness and earlier detection. Diabet Med. 1998;15(Suppl. 4):S60-S62. 
25. Leiter LA, Barr A, Belanger A, Lubin S, Ross SA, Tildesley HD, et al. Diabetes Screening in Canada (DIASCAN) Study: Prevalence of undiagnosed diabetes and glucose intolerance in family physician offices. Diabetes Care. 2001;24:1038-43.

26. Harding AH, Sargeant LA, Welch A, Oakes S, Luben RN, Bingham $\mathrm{S}$, et al. Fat Consumption and HbA1c Levels: The EPIC-Norfolk Study. Diabetes Care 2001;24:1911-6.

27. Yusuf S, Hawken S, Ônpuu S, Bautista L, Franzosi MG, Commerford P, et al. Obesity and the risk of myocardial infarction in 27000 participants from 52 countries: a case-control study. The Lancet 2005;366:1640-49.

28. Ramachandran A, Snehalatha C, Viswanathan V, Viswanathan M, Haffner SM. Risk of noninsulin dependent diabetes mellitus conferred by obesity and central adiposity in different ethnic groups- a comparative analysis between Asian Indians, Mexican Americans and Whites. Diabetes Res Clin Prac 1997;36:121-5.

29. Ramachandran A, Snehalatha C, Dharmaraj D, Viswanathan M. Prevalence of glucose intolerance in Asian Indians: Urban rural difference and significance of upper body adiposity. Diabetes Care 1992;15:1348-55.

30. Ruggenenti P, Fassi A, Ilieva AP, Bruno $\mathrm{S}$, Iliev IP, Brusegan V, et al. Preventing Microalbuminuria in Type 2 Diabetes: for the Bergamo Nephrologic Diabetes Complications Trial (BENEDICT) Investigators. N Engl J Med 2004;351:1941-51.

31. Dinneen SF, Gerstein HC. The association of microalbuminuria and mortality in non-insulindependent diabetes mellitus: a systematic overview of the literature. Arch Intern Med 1997;157:1413-8.

32. Meigs JB, Nathan DM, D'AgostinoRB sr, Wilson PW. Fasting and postchallenge glycemia and cardiovascular disease risk: the Framingham Offspring Study. Diabetes care 2002;25:184550.

33. Singer DE, Nathan DM, Anderson KM, Wilson PWF, Evans JC. Association of HbAlc with prevalent cardiovascular disease in the original cohort of the Framingham Heart Study. Diabetes 1992;41:202-8.

34. The DECODE Study Group. Glucose tolerance and cardiovascular mortality: comparison of fasting and 2-hour diagnostic criteria. Arch Intern Med. 2001;161:397-405.
35. Coutinho M, Gerstein HC, Wang Y, Yusuf S. The relationship between glucose and incident cardiovascular events: a metaregression analysis of published data from 20 studies of 95,783 individuals followed for 12.4 years. Diabetes Care 1999;22:233-40.

36. Edelman D, Olsen MK, Dudley TK, Harris AC, Oddone EZ. Utility of Hemoglobin A1c in Predicting Diabetes Risk. J Gen Intern Men. 2004;19:1175-80.

37. Blake GJ, Pradhan AD, Manson JE, WilliamsGR, Buring J, Ridker PM, et al. Hemoglobin A1c Level and Future Cardiovascular Events Among Women Arch Intern Med. 2004;164:757-61.

38. UK Prospective Diabetes Study Group. Intensive blood-glucose control with sulphonylureas or insulin compared with conventional treatment and risk of complications in patients with type 2 diabetes (UKPDS 33). Lancet 1998;352:83753.

39. Kuusisto J, Mykkanen L, Pyorala K.. NIDDM and its metabolic control predict coronary heart disease in elderly subjects. Diabetes 1994;43(8):960-7.

40. Levin ME, Sicard GA, Rubin BG. Peripheral vascular disease in the diabetic patient. In: Porte D Jr, Sherwin RS (eds). Ellenberg and Rifkin's Diabetes Mellitus. $5^{\text {th }}$ ed. Place of publication: Stamford, CT, Appleton \& Lange; 1997. P. 1127-58.

41. Olson JC, Erbey JR, Forrest KYZ, Williams K, Becker DJ, Orchar TJ. Glycemia (or, in Women, Estimated Glucose Disposal Rate) Predict Lower Extremity Arterial Disease Events in Type 1 Diabetes. Metabolism 2002;51:248-54.

42. The Diabetes Control and Complications Trial Research Group. The effect of intensive treatment of diabetes on the development and progression of diabetes on the development and progression of long-term complications in insulin-dependent diabetes mellitus. N Engl J Med. 1993;329:977-86

43. The Diabetes Control and Complications Trial/ Epidemiology of Diabetes Interventions and complications (DCCT/EDIC) Study Research Group. Intensive Diabetes Treatment and Cardiovascular Disease in Patients with Type 1 Diabetes. N Engl J Med. 2005;353:2643-53. 